\title{
A Refined Basket of Goods Approach for Comparing Construction Costs between Countries
}

\author{
Rick Best (Mirvac School of Sustainable Development, Bond University, Gold Coast, Australia)
}

\section{ABSTRACT}

Most comparisons of construction industry performance require that construction costs be converted to a common base. Existing mechanisms for such conversions produce unreliable results. A proposed method for producing industry-specific conversion factors was tested using a single building type. A basket of materials and labour was identified and weighted to reflect the cost share of each item in a completed project. Prices for the basket were gathered in three cities and simple construction specific conversion indices were calculated based on the construction purchasing power of each currency. The construction purchasing power parities (CPPPs) showed marked differences from other available conversion mechanisms such as exchange rates and general purchasing power parities (PPPs) that have been used in previous international comparison studies. While the study was limited in scope, and is only the first stage of a longer process, the substantial differences in comparative costs based on purchasing power illustrate the problems inherent in international cost comparisons. For example, comparing Singapore and Sydney, Singapore costs appear to be only $40 \%$ of those in Sydney (based on exchange rates) about two-thirds the cost of Sydney (using general PPPs) or almost the same (using the preliminary CPPPs). These results illustrate the problems of converting costs from local currencies to a single base currency and suggest that further development is needed to improve the reliability of outcomes.

Keywords: purchasing power parity, construction costs, international comparisons, Australia, New Zealand, Singapore.

\section{INTRODUCTION}

The lack of a consistent and reliable cost conversion mechanism for comparing construction costs internationally has been acknowledged (Best, 2007; Walsh and Sawhney, 2002, 2005; Blake et al., 2004; Stapel, 2002) and it has been demonstrated (Best and Langston, 2006a, 2006b) that the use of different conversion factors in comparative studies can produce quite contradictory outcomes. As a mechanism for bringing costs to a common base, exchange rates are too volatile and too much affected by a range of factors such as interest rates and changes of government (Schreyer and Koechlin, 2002; Goodchild and Griffiths, 2004). Purchasing power parities (PPPs) are routinely produced by several agencies but these are intended for use at the level of national economies and GDP. They are not recommended for comparisons at the level of individual industries (Goodchild and Griffiths, 2004; Danish Agency for Trade and Industry, 2000; Stapel, 2002, 2004) as they are based on a very large basket of items of which construction is only a part.

While construction specific purchasing power parities (CPPPs) are produced for a range of countries (OECD, 2005), these are not considered to be reliable by many (e.g. Ive et al., 2004; BWA, 2006; Blake et al., 2004) and are not available for many non-OECD countries. This paper describes the first stage of the development and testing of an improved method for producing constructionspecific purchasing power parities.

\section{THE LAW OF ONE PRICE}

The foundation of the purchasing power parity idea is the so-called Law of One Price. It is based on what Rogoff (1996:647) describes as "the disarmingly simple empirical proposition that the cost of a good or service (or a basket of goods and services), once prices are converted to a common currency, should cost the same in different countries". Fundamental to the PPP doctrine is the notion that similar items (or baskets of similar items) are worth the same (i.e. have the same value) in various places and therefore the amount of local money necessary to buy such items in one location is equivalent to the amount of money in other local currencies needed to buy the same items in those other locations (i.e. the equivalent amounts of the various local currencies have the same purchasing power).

It has been suggested that the Law of One Price does not hold well for construction output (Vermande and van Mulligen, 1999) as built facilities are not tradeable (Schreyer and Koechlin, 2002), and are produced and consumed locally. Vermande and van Mulligen go on to explain that a large proportion of the cost of a building is made up of labour costs and basic materials such as bricks, sand and concrete. These are mostly produced locally rather than imported and therefore their costs are little affected by exchange rates.

This may be true of the majority of structural and envelope components of most buildings but the same is unlikely to be true for other building elements. For example, in recent years there has been a marked increase in the proportion of building costs represented by engineering services, and a significant part of services costs include manufactured items such as fans, pumps, chillers, generators and mechanical transportation (lifts and escalators). Many countries do not produce these items locally and therefore have to import them. Even some highly developed countries do not have local producers of some basic construction materials - Singapore, for example, imports all the cement that it uses. While such goods are obviously tradeable the built facilities into which they are incorporated should be considered as complex units of construction output and therefore such output represents a mixture of tradeable and non-tradeable goods.

Even labour may be a tradeable commodity - in Singapore, for example, much of the onsite building work is done by socalled 'guest workers' who are imported from countries such as Bangladesh where labour is relatively cheap. Similarly in the south western states of the United States (e.g. Arizona) which lie on or near the Mexican border, cheap migrant labour is readily available. While this labour may not be 'tradeable' in the normal sense, it is acting as a tradeable commodity as it does follow the pattern of arbitrage in that a commodity (labour in this case) is bought more cheaply in one place and sold in another; in this instance it just happens that it is the people performing the jobs that are transported rather than what they produce. As a consequence of 
globalisation, supervisory and managerial personnel are routinely despatched to projects in all parts of the world and thus their skills are tradeable inputs to the construction industry.

From the preceding paragraphs it can be seen that the constituents of construction may in fact be tradeable at a number of levels even though generally built facilities themselves are clearly not. This leads to the proposition that construction may be expected to follow the Law of One Price to a greater extent than suggested by Vermande and van Mulligen (1999). On this basis it is proposed that the appropriateness of various conversion factors may be tested by analysing the results obtained using various conversion factors and looking for those that produce costs that most closely reflect convergence of prices in different locations to a single price. Such convergence is exactly what would be expected if the Law of One Price were to hold perfectly for construction prices.

\section{PREVIOUS APPROACHES}

The International Comparison Program (ICP) has used a standard projects approach to gathering construction cost data for calculation of PPPs for many years, however, there has been ongoing criticism of this method (Dubner and McKenzie, 2002). More recently the ICP has adopted a different approach based on a basket of construction components (BOCC): see Walsh and Sawhney (2005) and World Bank (2007a). Meikle (2003) questioned the validity of that approach and suggested that a basket of goods (BOG) that includes various classes of labour would be more useful; Stapel (2002) reported on a preliminary trial of a BOG, and Davis Langdon (DLC, 2003) subsequently ran a more comprehensive trial using a larger basket of materials and four classes of labour.

Some comparative studies have applied simpler methods for direct cost comparisons: e.g. Lynton PLC (Lynton, 1993) used exchange rates averaged over the ten years previous to their study; Langston and de Valence (1999) applied the Big Mac Index (BMI). Subsequent studies (Langston and Best, 2005; Best and Langston, 2006b; Best, 2007) show that ten year averages appear no more consistent than other methods and the BMI does not appear to offer a viable alternative in the construction context.

\section{PROBLEMS WITH EXISTING METHODS}

There is no consensus on what is the best approach, although there is some level of agreement with the view that the standard projects approach, based on bills of quantities (BQ), is less than ideal (Vermande and van Mulligen, 1999) due to the difficulty of finding truly standard projects, problems with interpretation and pricing of $B Q$ items in different countries and the high cost of running pricing rounds due to the sheer number of items that need to be priced.

Meikle (2003) mapped the advantages and disadvantages of four common methods and suggested that a weighted BOG approach was the most promising, although he noted some shortcomings, particularly that input prices do not include contractors' margins and therefore do not reflect actual prices paid for construction work, and that it is considered simplistic and has been dismissed as unsuitable in the past. He used national input/output tables to determine weights for the various items in the basket. Walsh and Sawhney $(2002,2005)$, in favouring the BOCC approach; contend that the component level provides the best balance between accuracy and level of effort required. They weighted the components in their basket based on a systems approach (substructure, superstructure and so on) using cost data from completed projects.
Best (2010) considered the various approaches and proposed a weighted BOG, called the Building BLOC (basket of locally obtained commodities), and suggested that it would provide a cost effective method for gathering cost data with weightings based on analysis of priced BQs from real completed projects.

The proposed Building BLOC comprises a number of materials (and in some cases manufactured or pre-fabricated items such as sanitary fittings and window units that are not typically made on site) and several classes of labour. The composition of the basket is dictated by the need to keep the pricing instrument reasonably small in order to minimise the time needed for pricing and thus allow the gathering of multiple sets of prices in each location, however, the basket needs to be comprehensive enough to be reasonably representative of the range of work that occurs in typical projects. In order to test the proposed approach a preliminary price-gathering exercise was carried out based on a small basket of materials and labour, comprising six common materials and two classes of labour, and a single building type, a medium standard, medium rise suburban hotel. A BQ for a completed 4-5 star hotel project, priced by the successful tenderer, was analysed in order to identify the most cost significant materials and to calculate the cost shares of each of the those items.

The following sections describe the preliminary exercise, the composition of the basket, the process of determining weights (quantities) for each item and the results obtained from a sample pricing round conducted in three countries (Australia, New Zealand and Singapore)

\section{POPULATING THE BASKET (BUILDING BLOCS)}

In the Stage 1 study described here the aim was to develop a limited basket for just one type of building, however, the concept could be expanded to include a range of building types with weights applied to each type to produce a sectoral basket (for nonresidential buildings for example). Equally, in the study prices were sought from just three cities, one in each country, and therefore the results provide a conversion mechanism for converting prices between localities or whole countries. Once again, however, if sets of prices are obtained from a number of locations in any given country then national averages could be determined. Thus expansion of the Building BLOC approach provides a range of opportunities for further research.

This preliminary exercise was intended primarily as a test of the practicality of implementing the approach. The items in the basket were therefore chosen largely on an ad hoc basis, however, the items selected were considered to be some that could be easily and quickly priced by the respondents. As a consequence no services were included and this limitation must be acknowledged and the resultant CPPPs interpreted with this limitation in mind.

\section{Analysis of the priced BQ comprised several steps:}

- Adjustment of the total project cost to remove the cost of those sections of the works that were site/project specific and were therefore considered not to be representative of typical hotel projects, e.g. substructure, landscaping, demolition.

- Identification of the trades that contributed most to the adjusted total project cost, and then identification of the most cost significant items within those trades.

- Decomposition of unit rates for the cost significant items to identify labour and material components. 
- Calculation of the cost share of each material as a percentage of the adjusted total project cost (excluding GST).

- Identification of individual materials items that were considered representative of all the materials in a particular trade.

- Determination of quantities (volumes) of each representative material based on the cost shares calculated previously.

- Calculation of labour times for different classes of labour required for the installation/placement of the derived quantities of the selected materials.

The outcome of this process was a basket of inputs (materials and labour) with the volume of each component reflecting the cost share of that component relative to the adjusted total project cost.

\section{ADJUSTING THE TOTAL PROJECT COST}

The sample project is a 196 room hotel completed in suburban Sydney in 2004. The contract sum in the priced $B Q$ was $\$ 23,782,668$ (AUD) which included preliminaries as a separate line item $(\$ 3,096,194)$ and GST. A separate 'early works' contract covered excavation and substructure so no adjustment was required in respect of that part of the project, however, siteworks, demolition and landscaping were deducted as these vary according to the size and nature of each site and the associated costs are not part of the actual building cost. Preliminaries was also deducted as preliminaries costs are to some extent location specific - in Sydney, for example, preliminaries costs are substantially higher in the centre of Sydney's CBD than they are in suburban locations (Rawlinsons, 2007).

The initial adjusted project cost was $\$ 19,792,779$. As unit rates for materials and labour supply are generally quoted excluding tax this was further adjusted by deducting $10 \%$ GST giving the final adjusted project cost (APC) of $\$ 17,993,435$.

\section{IDENTIFYING AND WEIGHTING ITEMS IN THE BASKET}

The process for identifying and weighting items in the basket is best illustrated with a couple of examples.

\section{MATERIALS}

A single material item is used here to demonstrate the identification and weighting process used. In the priced $B Q$ the total cost (excluding GST) for formwork was $\$ 915,875$, or $5.1 \%$ of the APC, making it the sixth most costly trade in the $B Q$. While various classes of formwork were specified, the most common was Class 3 , with items relating to Class 3 formwork totalling $\$ 812,942$, or $88.7 \%$ of the total formwork cost. Of the items for Class 3 formwork it was assumed that 'formply' would be the primary material used in forms to slab soffits, columns, stair landings and soffits, attached beams and walls. Indicative labour/materials splits were obtained from published data (Cordell, 2007) for each type of formwork and the number of re-uses of formply estimated for each situation. Unit rates for major items such as formwork to slab soffits were decomposed using the labour/materials splits; materials costs were then extracted in respect of the different locations and the different estimates of re-use.

The total cost in the $B Q$ for Class 3 formwork to slab soffits was $\$ 361,054$. Published unit rates (Cordell, 2007) were used to ascertain not only labour/material splits but to estimate actual costs of materials within those published rates as follows:

- The published rate for soffit formwork $\left(\$ 68 / \mathrm{m}^{2}\right)$ includes $\$ 55 /$ $\mathrm{m}^{2}$ labour and $\$ 13 / \mathrm{m}^{2}$ for materials (both excluding GST): this must include bearers, sole plates, nails and the like. The cost of formply was estimated to be $\$ 8 / \mathrm{m}^{2}$ - the small component $\left(\$ 5 / \mathrm{m}^{2}\right)$ for falsework and consumables reflects the potential for many re-uses of timber bearers and the like, and the relatively small contribution of consumables (nails, form oil) to formwork costs. The purchase cost of formply (Cordell, 2007 ) is $24.98 / \mathrm{m}^{2}$, suggesting three uses of formply in this situation. Thus the cost of formply was derived by multiplying the total for soffit formwork $(\$ 361,054)$ by the estimated rate for formply $\left(\$ 8 / \mathrm{m}^{2}\right)$ divided by the unit rate for soffit formwork $\left(\$ 68 / \mathrm{m}^{2}\right)$ :

$$
\$ 361,054 \times \frac{6}{68}=\$ 42,477 \text { (total cost of formply for soffits) }
$$

- The process was repeated using appropriate material/labour splits for the other Class 3 formwork items, with the total estimated cost of formply for Class 3 formwork being $\$ 89,477$ (excluding GST).

- This was then calculated as a fraction of the APC:

$$
\frac{\$ 89,477}{\$ 17,993,435}=0.004972 \text {, or } 0.4972 \%
$$

For the Stage 1 study a similar process was used for five other items selected at random from a list of twenty or so materials that were identified as the most cost significant materials in the project. Given the level of approximation in the calculations, percentages were rounded up to two decimal places.

In each case one item was selected and assumed to represent all similar items in the BQ: e.g. in the Masonry trade concrete blocks were identified as the most cost significant item, with 140 hollow blocks the most commonly occurring type of block - these were then assumed to represent blocks of all types. From the $B Q$ analysis it was determined that $\$ 117,638$ (out of a trade total of $\$ 229,759$ ) related to "hollow block" items. Published data (Cordell, 2007) suggests a labour/material ratio of 64:36 for hollow blockwork so block supply cost was calculated as $0.36 \times \$ 117,638$ $=\$ 42,350$, or $0.2354 \%$ of the APC. The most common type of block, 140 hollow, was then assumed to be representative of all blocks in the project.

The six selected items and the proportions of the APC that they represent were:

1. 140 hollow concrete blocks $(0.24 \%)$

2. Acrylic paint $(0.18 \%)$

3. 32MPa ready mixed concrete, delivered (1.77\%)

4. Precast concrete panels $(0.73 \%)$

5. Carpet, $80 / 20$ wool blend $(1.10 \%)$

6. 17 thick formply $(0.50 \%)$

Total supply costs for the six materials were calculated through analysis of the priced $B Q$ and these were divided by published 
2003 unit costs (Cordell, 2003) to derive quantities of each item for inclusion in the basket. Analysis of labour/material/plant splits for the six items (Cordell, 2007) provided basic labour to materials ratios for the selected items. As the fraction of the total that is plant cost in the selected items is relatively small and major plant is presumed to be included in preliminaries (e.g. tower crane, concrete pumps), the plant component was ignored and simple labour/material ratios adopted.

Weightings were adjusted to represent the fractions of the individual material costs in the basket, e.g.:

$$
\text { Formply: } \frac{0.4972}{4.5132}=0.11
$$

i.e. formply represented $0.11(11 \%)$ of the cost of the mini basket (4.5132 was the sum of the weights for the six material items in the basket). If materials in total represent $43 \%$ of the basket then formply will represent $0.11 \times 43 \%=$ $4.73 \%$ of the total $(L+M)$ mini basket.

Similar calculations yielded the following weights for the remainder of the items:

\section{Hollow blocks: $2.28 \%$}

\section{Paint: $1.70 \%$}

\section{Concrete: $17.18 \%$}

4. Precast concrete: $7.09 \%$

\section{Carpet $10.67 \%$}

Quantities of each item in the basket were calculated as follows. The total supply cost for each selected item in the BQ was calculated as previously described. Dividing this by the 2003 supply cost for each item (Cordell, 2003) gave a derived quantity for each item. These quantities set the scale for the materials in the basket, based on the size of the original project that was analysed. It is not suggested that the derived quantities are the actual quantities of these items in the sample project but rather they indicate of the scale of the quantities of the particular type of material in the sample project: e.g. 140 hollow blocks as the material representing all blocks in the project. The scale of the quantities provides context (in terms of project size) for pricing.

\section{LABOUR}

It is difficult to ascertain accurate ratios for different classes of labour in respect of individual $B Q$ items or of trades in general. Meikle (2003) in his trial BOG used a split of 10:30:30:30 for supervision, skilled, semi-skilled and unskilled labour, but this was largely notional based on his experience and knowledge of the industry. In this study supervision was assumed to be included in preliminaries and labour splits were estimated based on published data where available and on this author's experience. It should be noted that some supervisory labour cost will be included in unit rates, particularly those for sub-contract work. It will therefore be part of the labour component in the rate breakdowns. The proportion of such labour within the overall labour cost and the degree of difference between supervisor rates and tradesman rates is expected to be small enough that any resultant distortion of outcomes can be ignored.

In Sydney, site labour may be divided into various classes based on pay levels: tradesmen (in several broad classes with Class 1 including electricians and plumbers, Class 2 including carpenters and joiners, and Class 3 painters, plasterers, tilers and masons) semi-skilled labour (e.g. concrete placers) and unskilled (general labourer). Labour required for installation of the six material items in the basket was identified (e.g. carpet laying was assumed to be $100 \%$ Class 3 tradesman, block laying as $80 \%$ Class 3 tradesman and $20 \%$ semi-skilled labourer) and weights calculated based on the relative weights of labour and material for each item. For example, as noted earlier, for hollow blocks the labour/material split is $64: 36$ and the derived supply cost was $\$ 42,350$. The labour cost associated with that quantity of blocks was then:

$$
\frac{\$ 42,350 \times 0.64}{1-0.64}=\$ 75,289
$$

and of that amount $80 \%(\$ 60,231)$ is for tradesmen and $20 \%$ $(\$ 15,058)$ is semi-skilled or unskilled labour.

\section{THE MINI BASKET OR 'BUILDING BLOC'}

Using the procedures outlined above the following tables (Tables 1, 2 and 3) were completed and the mini basket or Building BLOC was extracted (Table 4). Table 1 shows the calculations for quantities of materials for the mini basket, Table 2 shows the calculation for each class of labour; and Table 3 shows the derivation of labour hours. Given that the labour ratios are to some extent notional and that there are likely to be differing divisions of labour in different locations, and to minimise the effort required for pricing, just two classes of labour were used for this study, skilled tradesman and semi-skilled labour. In the pricing instructions included with the basket the labour types were explained with 'tradesman' being identified as, for example, blocklayers and painters, and 'semi-skilled' as, for example, concrete placers and precast fixers. All labour was calculated to represent $57 \%$ of the basket, with tradesman hours representing $25.81 \%$ and semiskilled labour $31.57 \%$ of the total basket. Total costs for each class of labour were divided by 2003 hourly rates (Cordell, 2003) to derive the number of hours of each type of labour associated with all the material items in the basket.

\section{THE SURVEY}

A short survey and some explanatory notes that provided directions on how the pricing was to be done (e.g. excluding/ including VAT/GST) were distributed with the list of materials and labour to a number of quantity surveying (QS) and contracting firms in three cities; Sydney, Auckland and Singapore. As this survey was a preliminary exercise for a larger study the survey was sent to individuals known to the author or through people known to the author who could direct the survey to appropriate personnel in each firm.

Apart from questions related to unit rates, respondents were asked to provide an estimate of contractors' margins (profit and overheads), estimated preliminaries cost for a project of the size and type described (3-4 star multi-storey inner suburban hotel) and the current state of the tendering market in their city. They were also asked about tender price levels relative to the state of the market in their location. The aim was to determine if some adjustment to basket costs for market conditions might be warranted, and if so how big the adjustment should be. This line of questioning was not very successful with many responses suggesting that the question was not well understood. In consultation with one of the respondents the question was reworded and respondent asked to reassess their previous answers. 
Table 1: Calculation of material quantities

\begin{tabular}{|c|c|c|c|c|c|c|}
\hline \multicolumn{7}{|l|}{ MATERIALS } \\
\hline Item & $\begin{array}{r}\text { Material } \\
\text { cost in BQ } \\
(2003 \$, \\
\text { ex GST })\end{array}$ & $\begin{array}{r}\text { Generic } \\
\text { material as } \\
\% \text { age of } \\
\text { APC }\end{array}$ & $\begin{array}{r}\text { Material } \\
\text { cost as } \\
\% \text { age of } \\
\text { BLOC }\end{array}$ & \begin{tabular}{|} 
Unit rate \\
$(2003 \$)$
\end{tabular} & Unit & $\begin{array}{l}\text { Derived } \\
\text { quantity }\end{array}$ \\
\hline Hollow blocks & 42350 & $0.24 \%$ & $5.40 \%$ & 1.79 & No & 23659 \\
\hline Paint & 31595 & $0.18 \%$ & $4.03 \%$ & 8.00 & L & 3949 \\
\hline 32MPa concrete & 318894 & $1.77 \%$ & $40.66 \%$ & 175.00 & m3 & 1822 \\
\hline Precast concrete & 131659 & $0.73 \%$ & $16.79 \%$ & 75.00 & $\mathrm{~m} 2$ & 1755 \\
\hline Carpet & 170318 & $0.95 \%$ & $21.72 \%$ & 40.00 & $\mathrm{~m} 2$ & 4258 \\
\hline Plywood for formwork & $\underline{89477}$ & $\underline{0.50 \%}$ & $11.41 \%$ & 25.97 & $\mathrm{~m} 2$ & 3445 \\
\hline Totals & 784294 & $4.36 \%$ & $100 \%$ & & & \\
\hline
\end{tabular}

Table 2: Calculation of labour costs

\begin{tabular}{|c|c|c|c|c|}
\hline \multicolumn{5}{|l|}{ LABOUR } \\
\hline Item & $\begin{array}{r}\text { Labour } \\
\text { cost } \\
(2003 \$)\end{array}$ & $\begin{array}{r}\text { Derived } \\
\text { labour } \\
\% \text { age }\end{array}$ & $\begin{array}{r}\text { Trades- } \\
\text { man } \\
\$\end{array}$ & $\begin{array}{r}\text { Semi- } \\
\text { skilled } \\
\$\end{array}$ \\
\hline Hollow blocks & 75289 & $64 \%$ & 60231 & 15058 \\
\hline Paint & 94786 & $75 \%$ & 94786 & \\
\hline $32 \mathrm{MPa}$ concrete & 124014 & $28 \%$ & & 124014 \\
\hline Precast concrete & 374722 & $74 \%$ & & 374722 \\
\hline Carpet & 50874 & $23 \%$ & 50874 & \\
\hline Plywood for formwork & $\underline{336605}$ & $79 \%$ & $\underline{269284}$ & $\underline{67321}$ \\
\hline Totals & 1056291 & & 475175 & 581115 \\
\hline
\end{tabular}

Table 3: Calculation of labour quantities

\begin{tabular}{|c|c|c|c|c|}
\hline LABOUR & $\begin{array}{r}\text { Labour cost } \\
(2003 \$)\end{array}$ & $\begin{array}{r}\text { Unit rate } \\
(2003 \$)\end{array}$ & $\begin{array}{l}\text { Derived } \\
\text { quantity }\end{array}$ & Unit \\
\hline Tradesman & 475175 & 48.00 & 9899 & hrs \\
\hline Semi-skilled & 581115 & 37.50 & 15496 & hrs \\
\hline
\end{tabular}

Table 4: Mini basket of goods (BLOC) rounded quantities

\begin{tabular}{|l|r|r|}
\hline MATERIALS & Unit & Quantity \\
\hline 140 blocks & No. & 24000 \\
\hline Acrylic paint & $\mathrm{L}$ & 4000 \\
\hline $32 \mathrm{MPa}$ concrete & $\mathrm{m}^{3}$ & 1800 \\
\hline Precast concrete & $\mathrm{m}^{2}$ & 1750 \\
\hline $80 / 20$ carpet & $\mathrm{m}^{2}$ & 3800 \\
\hline 17 formply & $\mathrm{m}^{2}$ & 3400 \\
\hline LABOUR & & \\
\hline Tradesman & hours & \\
\hline Semi-skilled & hours & \\
\hline
\end{tabular}




\section{RESULTS}

Eight responses were collected from Sydney (three QS, five contractors), six from Auckland (three QS, three contractors) and six from Singapore (four QS, two contractors) - 20 in total (10 QS, 10 contractors). While the sample is small it provided useful insights into the process and highlighted the need to distribute the main survey widely in the industry in order to gather a useful sample of prices, as eliciting responses from firms for even the small survey that was used in this exercise was very difficult, even when the average time to complete the survey was just 17 minutes (median: 15 minutes).

An average rate for each material and labour item was calculated for each location. These unit rates were applied to the rounded derived quantities in the basket to produce a total cost for the basket in each local currency. From these basket costs CPPPs were derived relative to one AUD. Table 5 shows the basket costs, and Table 6 the CPPPs based on the whole basket and on the materials component only, with and without the addition of the average estimated contractors' margins. It also shows a range of other possible conversion factors.

With regard to market conditions it emerged that in both Sydney and Auckland respondents generally agreed that current prices were currently close to average levels (i.e. neither inflated due to an abundance of work and weak competition, nor deflated due to scarcity of work and strong competition) and therefore there would no reason for any adjustment. In Singapore, however, the respondents unanimously agreed that the market was booming and that tender prices were around $20 \%$ higher than would be expected in an average market. If the cost of the basket is deflated by $20 \%$ to bring the price in line with average tender price levels then the CPPP becomes just 0.40SGD = 1AUD (based on the cost of the Building BLOC including contractors' margin).

\section{DISCUSSION}

Within the constraints of this preliminary study (i.e. a small number of material and labour items and a small number of responses from each location) a number of significant results are easily identified from Table 6

- As might be expected, the use of exchange rates to compare construction costs is likely to produce quite distorted results.

- The Big Mac Index (BMI) also appears quite unsuitable for conversions between the locations surveyed in the this study.

- $\quad$ The derived CPPPs are markedly different to the other factors that might be used such as ICP PPPs.

- $\quad$ The use of Penn World Tables (PWT) PPPs from 2004 and ICP PPPs from 2005 (the most recent available) illustrates the problems associated with the intermittent publication of PPPs; furthermore, published CPPPs could not be located for Singapore for any year.

- For both Auckland and Singapore it is the difference in labour costs that is the major cause of the divergence of the CPPPs from other conversion factors (relative to the Australian dollar).

- The inclusion or exclusion of contractors' margins makes little difference to the derived CPPPs.

\section{EXCHANGE RATES AND THE BIG MAC INDEX}

The Singapore/Australia comparison in Table 6 illustrates the difference in the conclusions that may be drawn about relative costs of construction in the two locations depending on the conversion method used. Rawlinsons (2007) suggests an average cost for hotel construction in Sydney in 2007 as AUD\$3,150/ $\mathrm{m}^{2}$ and SGD $\$ 1,650 / \mathrm{m}^{2}$ in Singapore. If exchange rates are used to compare the two rates the Singapore rate then becomes AUD $\$ 1,304 / \mathrm{m}^{2}$ and that would suggest that the cost of hotel construction in Singapore in 2007 was just $40 \%$ of the cost in Sydney. This could be taken to mean that hotel construction in Singapore is cheaper and therefore the industry is considerably more competitive and perhaps considerably more efficient. Such conclusions have been drawn in earlier studies (e.g. Page Kirkland, 1999). Best and Langston (2006b) clearly demonstrated that such conclusions are dubious. If the BMI is used in a similar fashion, equally questionable conclusions could be drawn.

If, however, the CPPP derived from the preliminary study is used (1AUD $=0.485 S G D$ ) the Singapore rate becomes SGD $\$ 3,402 / \mathrm{m}^{2}$ and it then appears that Singapore may be, based on purchasing power parity, slightly more expensive than Sydney. It should be noted that PPPs are not absolute measures (Goodchild and Griffths, 2004; World Bank, 2007b) and therefore it would be more accurate to say that construction costs, in terms of 'construction dollars', are quite similar in the two cities.

\section{OTHER PPPS}

The most recent PPPs from the PWT and the ICP have been used and these sit between exchange rates/BMI and the derived CPPPs. The time lag that is evident is an ongoing problem - the latest ICP PPPs were released in 2007 but are benchmarked to 2005 , so it is possible that there have been changes in PPPs since the benchmark year that may alter the outcomes here. If the more recent PPPs (i.e. the 2005 ICP) are used then the Singapore rate $/ \mathrm{m}^{2}$ for hotel construction becomes AUD $\$ 2,099 / \mathrm{m}^{2}$. This still suggests that Singapore is around 33\% cheaper than Sydney.

\section{DIFFERENCES IN LABOUR AND MATERIAL COSTS}

CPPPs were calculated based on the whole basket and on the material component only. For both Auckland and Singapore the material only values vary markedly from the whole basket values although the effect is much greater for Singapore. In both cases the materials only CPPP is quite similar to the respective PWT and ICP PPPs.

Labour costs in Singapore are, by any measure, lower than in Sydney or Auckland. UBS (2006) showed unskilled/semi-skilled building labourers in Singapore earning around $70 \%$ of those in Auckland and only slightly more than half that earned by their Australian counterparts. Although incomes were compared in the UBS study using exchange rate conversion the difference is emphasised by the comparison of the time that an average worker in Singapore has to work in order to buy several basic food items. Table 7 illustrates this, with the Singapore worker having to work double the time that a worker in Sydney or Auckland works in order to buy each of the three items (see UBS, 2006:11). It should be noted, however, that the number of labour hours in the basket are based on analysis of a Sydney project and therefore reflect the productivity of Sydney workers; if similar projects were analysed it may be that the lower labour rates would, to some extent at least, be offset by lower productivity. 


\begin{tabular}{|c|c|c|c|c|c|c|c|c|c|c|c|}
\hline \multicolumn{3}{|l|}{ Mini BLOC } & \multicolumn{3}{|c|}{ Average Rates } & \multicolumn{3}{|c|}{ MiniBLOC costs $(M+L)$} & \multicolumn{3}{|c|}{ Mini BLOC costs incl. margins } \\
\hline Item & Unit & Qty & AUD & NZD & SGD & AUD & NZD & SGD & AUD & NZD & SGD \\
\hline Hollow blocks & No & 24000 & 2.04 & 2.26 & 1.21 & 48900 & 54160 & 29000 & 52079 & 56868 & 31755 \\
\hline Paint & $\mathrm{L}$ & 4000 & 9.95 & 10.78 & 6.96 & 39800 & 43100 & 27833 & 42387 & 45255 & 30478 \\
\hline 32MPa concrete & $\mathrm{m}^{3}$ & 1800 & 159.00 & 187.83 & 133.33 & 286200 & 338100 & 240000 & 300510 & 355005 & 262800 \\
\hline Precast concrete & $\mathrm{m}^{2}$ & 1750 & 212.86 & 170.00 & 144.17 & 372500 & 297500 & 252292 & 396713 & 312375 & 276259 \\
\hline Carpet & $m^{2}$ & 3800 & 32.50 & 33.13 & 54.17 & 123500 & 125875 & 205833 & 131528 & 132169 & 225388 \\
\hline Plywood & $m^{2}$ & 3400 & 32.14 & 30.60 & 14.24 & 109286 & 104046 & 48427 & 116389 & 109248 & 53028 \\
\hline Skilled labour & hrs & 9900 & 57.13 & 39.57 & 11.83 & 565538 & 391710 & 117150 & 602297 & 411296 & 128279 \\
\hline Semi-skilled labour & hrs & 15500 & 45.94 & 30.90 & 10.17 & 712031 & 478950 & 157583 & 758313 & 502898 & 172554 \\
\hline TOTALS & & & & & & 2169054 & 1736181 & 1021286 & 2305750 & 1822990 & 1118308 \\
\hline
\end{tabular}

Table 6: Conversion factors relative to AUD $\$ 1$

\begin{tabular}{|l|r|r|r|r|r|r|r|r|}
\cline { 2 - 8 } & $\begin{array}{r}\text { CPPP (all) } \\
\text { No margin }\end{array}$ & $\begin{array}{r}\text { CPPP (all) } \\
\text { Inc. margin }\end{array}$ & $\begin{array}{r}\text { CPPP } \\
\text { (materials) } \\
\text { No margin }\end{array}$ & $\begin{array}{r}\text { CPPP } \\
\text { Inc. margin }\end{array}$ & $\begin{array}{r}\text { Penn WT } \\
\text { InPP } \\
(2004)\end{array}$ & $\begin{array}{r}\text { ICP } \\
\text { PPPs } \\
(2005)\end{array}$ & $\begin{array}{r}\text { Exchange } \\
\text { rates } \\
(02 / 08)\end{array}$ & $\begin{array}{r}\text { Big Mac } \\
\text { Index } \\
(07 / 07)\end{array}$ \\
\hline Auckland & 0.812 & 0.802 & 0.981 & 0.972 & 1.029 & 1.071 & 1.138 & 1.333 \\
\hline Singapore & 0.481 & 0.495 & 0.827 & 0.854 & 0.892 & 0.786 & 1.265 & 1.145 \\
\hline
\end{tabular}

Table 7: Working time required to buy typical food items (Source: UBS, 2006)

\begin{tabular}{|l|c|c|c|}
\cline { 2 - 4 } \multicolumn{1}{c|}{} & \multicolumn{3}{c|}{ Working time (mins.) needed to purchase } \\
\hline City & Big Mac & $\mathbf{1 ~ k g}$ of rice & $\mathbf{1 ~ k g}$ of bread \\
\hline Sydney & 14 & 5 & 15 \\
\hline Auckland & 14 & 5 & 13 \\
\hline Singapore & 26 & 10 & 26 \\
\hline
\end{tabular}




\section{CONTRACTORS' MARGINS}

The basket of goods approach has been criticised because it is based on input prices and so does not directly include contractors' margins for profit and general overheads (Stapel, 2002; Walsh and Sawhney, 2004). In the Stage 1 survey respondents were asked to provide an estimate of contractors' markups for a project of the type analysed to produce the Building $B L O C$. CPPPs were calculated based on the cost of the Building $B L O C$ with and without the addition of the average estimated markup for each city. As Table 6 showed, the two CPPPs for both places vary only slightly with the inclusion of markups and this suggests that the unless margins in some locations were considerably higher than in others then the question of markups is not important.

In this study the average estimated margins were Sydney (6.5\%), Auckland (5\%) and Singapore (9.5\%); the higher margin in Singapore reflects the current strong market there and could be accounted for by adjusting the Building BLOC cost for Singapore down to allow for the difference in market conditions between the three cities (tender markets in both Sydney and Auckland were both considered to be about average by the respondents in those places).

\section{CONCLUSION}

The work reported here is only the first of several stages in the development of a basket of materials and labour for the production of construction industry PPPs. The purpose of the preliminary study described here was to test the proposed Building BLOC approach empirically and ascertain whether it could be applied in practice as a mechanism for the production of industry-specific PPPs. The data obtained using the approach was shown to be sufficient to allow the calculation of simple PPPs, based on the total cost of the basket or Building BLOC in each city.

Given the restricted scope of this initial exercise, no firm conclusions can be drawn from it, however indicative CPPPs were produced that show quite different relativities between construction costs than those obtained using other methods, including general PPPs. Singapore was shown to be at least as expensive a place to build as Sydney or Auckland, when costs were converted to AUD using these preliminary CPPPs. In contrast, if published $\$ / \mathrm{m}^{2}$ rates for a typical hotel building are converted to AUD using exchange rates, the Singapore cost appears to be less than half the Sydney cost. Even if other purchasing power based indices, not specific to construction, are used Singapore still appears to be considerably less expensive. These results suggest at least that other conversion methods are producing distorted outcomes and indicate that the proposed method is worthy of further development.

On balance it appears that the method used improves on previous versions of the BOG approach by addressing several areas of concern associated with earlier models. The study showed that while data relating to contractors' margins can be obtained, the inclusion or exclusion of margins in the Building $B L O C$ calculations produces only minor differences in the final CPPPs and in most cases will not pose a significant problem. Further investigation of this aspect of the study is warranted, however, as the adjustment of input costs to purchaser prices is a key feature of the Building BLOC approach and dealing with margins appropriately is an important part of that process.
The robustness of the method is substantially improved by the use of real projects to identify cost significant items and to assign weights to the items that are included in the basket. The input/output approach used by Meikle, while appearing to be conceptually sound, has the limitation that it is difficult to produce anything other than two country comparisons and therefore is of restricted value in the formulation of national indices. The components included in the basket of goods used in Meikle's trial and in the World Bank's BOCC, while based on the knowledge of experienced experts, have no clear basis for their inclusion in terms of their significance in the overall cost of construction. For example, the World Bank's BOCC includes just one services item, a single electrical outlet, while a quick analysis of the Eurostat/ Meikle basket shows that only $20 \%$ of the material items relate to engineering services elements (and six of the seven were plumbing/drainage materials) yet cost analyses of most types of non-residential buildings (and this also may include high rise apartments) show that in modern buildings $50 \%$ or more of the cost can be in the services. The Stage 1 study did not include any services items and further work is required in order to rectify that shortcoming and assemble a more representative basket.

Other concerns that need to be addressed include the need to establish labour ratios that are representative of the various building types and categories of construction and to identify various representative baskets and weight them appropriately to determine if there are significant differences between baskets for different building types and/or different locations. This will entail a good deal of analysis of completed projects, however, the relative ease of pricing, given the extent and nature of the baskets, would make more frequent pricing at multiple locations by multiple individuals an economically viable exercise and should provide a much better range of input prices resulting in more accurate (or better ) indices. This is precisely what both Eurostat and the World Bank (through their International Comparison Program) are looking for as construction cost data and CPPPs are a significant part of that work. One of the problems with the current methods used by Eurostat and the World Bank is that generally only one set of observations is collected from each country and that occurs on a 3-5 year cycle. A method that reduces implementation costs and thus allows more frequent pricing and the chance for multiple observations in each location in each pricing round should be of special interest to these organisations.

Therefore using Building BLOCs as a new form of exchange rate for international construction cost comparisons has promise.

\section{REFERENCES}

Best, R. (2010) 'Using 'building blocs' for international construction cost comparisons', in de Valence, G. (ed.) Modern construction economics, Spon Press (in press).

Best, R. (2007) 'Currency conversions for construction cost comparisons: purchasing power parities and exchange rates', in proceedings of Construction Management and Economics 25th Anniversary Conference, University of Reading, July 16-18.

Best, R. and Langston, C. (2006a) 'Evaluation of construction contractor performance: a critical analysis of some recent research', Construction Management and Economics, 24(4), 439-445.

Best, R. and Langston, C. (2006b) 'Converting construction costs to a common currency base: an unresolved problem', in proceedings of Construction in the XXIst Century: Local and Global Challenges, Rome, October 18-20. 
Blake, N., Croot, J. and Hastings, J. (2004) Measuring the competitiveness of the UK construction industry: volume 2, Experian business strategies, London: Department of Trade and Industry.

BWA (2006) Benchmarking of use of construction (costs) resources in the member states (pilot study), London: Bernard Williams Associates.

Cordell (2003) Cordell commercial and industrial building cost guide, Canberra: Reed Data Services, October.

Cordell (2007) Cordell commercial and industrial building cost guide, Canberra: Reed Data Services, July.

Danish Agency for Trade and Industry (2000) Construction costs in Denmark: a comparison with other countries, Copenhagen: Ministry for Business and Industry.

DLC (2003) An initial test exercise on a basket of goods approach to construction price comparisons, London: Davis Langdon Consultancy.

Dubner, M. and McKenzie, R. (2002) 'Construction industry purchasing power parities: obtaining comparable prices', in proceedings of Conference on the International Comparison Program, Washington, D.C., March 11-14 (available at http://www. worldbank.org/data/icp/documents/dms.doc).

Goodchild, G. and Griffiths, D. (2004) New Zealand's involvement in the joint OECD-Eurostat Purchasing Power Parities Programme, Statistics New Zealand Information Paper 2004.

Ive, G., Gruneberg, S., Meikle, J and Crosthwaite, D. (2004) Measuring the competitiveness of the UK construction industry: volume 1, London: Department of Trade and Industry.

Langston, C. and de Valence, G. (1999) International cost of construction study: stage 2, evaluation and analysis, Canberra: Department of Industry Science and Resources (available at hyyp://www.isr.gov.au/library/content_library/BC-CoCStage2.pdf).

Langston, C. and Best, R. (2005) 'Using the Big Mac Index for comparing construction costs internationally', in proceedings of QUT Research Week 2005, Queensland University of Technology, July 4-5.

Lynton (1993) The UK construction challenge, London: Lynton PLC.

Meikle, J. (2003) Summary comparison of approaches to international construction price comparisons, London: Davis Langdon Consultancy, unpublished.

OECD (2005) Purchasing power parities and real expenditures: benchmark year 2002, Paris: Organisation for Economic Cooperation and Development.

Page Kirkland (1999) International cost of construction study: stage 1, base cost of construction, Canberra: Department of Industry Science and Resources.

Rawlinsons (2007) Australian construction handbook 2007 (25th Edition) Perth: Rawlhouse Publishing.

Rogoff, K. (1996) 'The purchasing power parity puzzle', Journal of Economic Literature, XXXIV, 647-668.
Schreyer, P. and Koechlin, F. (2002) Purchasing power parities 1999 benchmark results, Paris: OECD Statistics Directorate.

Stapel, S. (2002) 'The Eurostat construction price surveys: history, current methodology and new ways for the future', in proceedings of International Conference on ICP, World Bank, Washington, 11-13 March.

Stapel, S. (2004) 'Challenging the 'snapshot theory' of purchasing power parities: Eurostat's revision of the PPP 1995 to 2000' (available at http://www.ipeer.ca/papers/Stapel,June6,2004,_ final_04_6_04.pdf).

UBS (2006) Prices and earnings: a comparison of purchasing power parity around the globe (2006 Edition), Zurich: Union Bank of Switzerland.

Vermande, H. and van Mulligen, P-H. (1999) 'Construction costs in The Netherlands in an international context', Construction Management and Economics, 17(3), 269-283.

Walsh, K. and Sawhney, A. (2002) International comparison of cost for the construction sector: towards a conceptual model for purchasing power parity, report submitted to the World Bank Group, June.

Walsh, K. and Sawhney, A. (2004) International comparison of cost for the construction sector: an implementation framework for the basket of construction components approach, report submitted to the African Development Bank and the World Bank Group, June.

Walsh, K. and Sawhney, A. (2005) International comparison of cost for the construction sector: identification of construction systems and components for the BOCC approach, report submitted to the World Bank Group, November.

World Bank (2007a) Construction sector comparison using the basket of construction components approach: executive summary (available at http://siteresources.worldbank.org/ICPINT/ Resources/Summary_of_BOCC_Approach.doc).

World Bank (2007b) 2005 International Comparison Program preliminary global report compares size of economies (available at http://web.worldbank.org/WBSITE/EXTERNAL/NEWS/0,, conte ntMDK:21589281 menuPK:34463 pagePK:34370 piPK:34424 t heSitePK:4607,00.html). 
